\title{
Language, Task and Situation: Authenticity in the Classroom
}

\author{
Ken Beatty \\ Anaheim University \\ Correspondence concerning this article should be addressed to Ken Beatty, 496 Melmore Road, Bowen \\ Island BC, Canada, V0N1G1.E-mail: kenbeatty@mac.com
}

\begin{abstract}
There is debate on the use of authenticity in language classrooms in terms of language, task, and situation. "Authenticity of language" spans a continuum that begins with inauthentic materials - wholly created by a teacher or materials developer - to constructed materials, modified from real-world materials, to those materials created for non-pedagogical L1 purposes. "Authenticity of task" questions whether students are engaging with language materials in a way that would appear natural outside the classroom. "Authenticity of situation" refers to non-classroom contexts. Complicating ideas of authenticity is the question of materials selection. This paper explores teachers' awareness of authenticity and suggests ways to incorporate authentic language, tasks, and situations to enhance classroom learning.
\end{abstract}

Keywords: Authenticity, curriculum development, English for academic purposes, teacher education

Authenticity is a relatively new concept in language teaching and learning first surfacing as a concern in the 1970s. It is also a slippery concept that has curiously defied definition despite repeated attempts. The act of trying to define authenticity means that the concept continues to evolve to the point where it now encompasses not just language (language content in particular) but also task and situation.

Struggling with the scope of what constitutes authenticity, Dunkel (1995) reflects on authentic discourse, authentic language and authentic materials and suggests, "Many in the field utilize these three terms in holistic, vague and imprecise ways and are unclear about precisely what is and what is not "authentic" (p. 98). She specifically cites the oft-repeated definition that authentic language is produced by and for native speakers of the language but suggests that the definition is too elusive to be of much help. Other attempts at defining authenticity run a continuum between general and specific and include Nunan (1988) who writes that authenticity is comprised of, "those [materials] which have been produced for purposes other than to teach language" (p. 99). The difficulty with this definition is that it is so broad to the point that it provides no direction to teachers and materials developers; if almost everything is authentic, how, then, do they make choices?
Rogers \& Medley (1988) seem aware of this pitfall and suggest that the criteria should include the quality, appropriateness and naturalness of the language rather than a simple consideration of the source and purpose of the sample of authentic language. Taking this perspective, it is easier to imagine the teacher excluding materials that might not be appropriate for a range of reasons including materials that do not feature age appropriate language or age appropriate content. For example, while the financial pages of an English language newspaper might be suitable for college students in an advanced-level English for Academic Purposes course, one would hardly expect the same materials to be used with primary school students struggling at a beginner level. Through this example, we get an idea of authenticity being not a generic term applied to language, tasks and situations, but rather a concept that needs to work in concert with the teacher's or material developer's understanding of the target language learners.

Widdowson (2012) seems to support this idea, suggesting that authentic language is a social construct and one open to interpretation. Widdowson's contribution is typical of the debate around authenticity in that it aims to illuminate one aspect without any attempt to be definitive. Widdowson also notes that authentic language has to do with a quality 
he labels genuineness. By genuineness, we can relate his perception of authenticity to those of Nunan (1988) and others, the idea that authentic language cannot be that developed specifically for the language student.

Cardew (2006, cited in Tatsuki, 2006), however, goes further, noting that authentic language materials, alone, do not guarantee that the lesson will be successful. It is not just the materials themselves which are important, but their implementation. This brief overview of definitions suggests that we are best to be skeptical about notions of authenticity and begin any discussion with a concern for the learners' needs and how we can best address those needs.

\section{Materials and Methods}

\section{Historical Perspectives}

An alternative way to define a concept such as authenticity is to consider its opposite. As authenticity is a relatively new idea in the history of language teaching and learning, it is possible to consider historical examples of textbooks that focused on authenticity to varying degrees. Among the first language learning textbooks is Orbis Sensulium Pictus (The Visible World in Pictures), a much-adapted textbook aimed at the teaching of local languages by Czech teacher, writer and educator Jon Amos Comenius (1592-1670) (Bardeen, 1887). The initial book and others that followed in the same pattern were revolutionary for their inclusion of pictures to bridge comprehension between what students already knew and the pronunciation of words they were intended to learn. The book was widely reprinted and adapted to a variety of languages, often in a bilingual fashion, for example, teaching English and Latin terms side by side. But, although the approach was innovative the language was far from authentic. Instead, it tried to teach reading and writing through general principles. In Orbis Sensulium Pictus, students learned sounds, words and sample sentences to better understand the structure of the target language.

The success of Orbis Sensulium Pictus (and adaptations that followed for two centuries) was such that it had a profound influence on other textbooks which adopted the same principles. Many of these, while following Orbis' format, introduced nationalistic and/or religious content. For example, The New England Primer, published in 1771, used memorable quotes to impart moral teachings alongside language acquisition (Foster, 2012). Typical of this book's approach were phrases such as, "Foolishness is bound up in the heart of a child, but the rod of correction will drive it far from him." In some ways this perspective of devaluing the worth and intelligence of the child is the opposite of Comenius' approach, whose goal was to enfranchise the poor as well as women, giving them opportunities for what he saw as the life-long learning enabling aspect of reading. But it is difficult to know what eighteenth century teachers and learners would have made of such a text and whether they would have taken such moral quotes seriously.

In terms of authenticity, it is unlikely that The New England Primer mirrored either writing or conversation of the time (Foster, 2012). It can further be assumed that the role of the student was not a concern to the materials developer; the idea of student-centeredness is a relatively recent concept (Nunan, 1988).

A hundred years later, another book modeled on Orbis Sensulium Pictus appeared: the influential The Monroe Reader, first published around 1871. Like Comenius' text, it also offered phonemic awareness but as a central focus rather than as supporting details. The opening page, Lesson 1 , Sounds of $m, n$ and short a featured the text $m$ a $n, m$ a $n$, man, an, am, man, man, an, am, a man. The accompanying picture featured a severe-looking gentleman posed next to a table. Although it might not feature the same kind of fear-inspiring quotes that The New England Primer included, it was similarly joyless and unlikely to have prompted active engagement in the acquisition of English. It has to be noted that learners often become proficient in language despite (poor) materials, not because of them.

Also influential were The McGuffey Readers, originally introduced in 1836 and used in American schools into the $20^{\text {th }}$ century; some remain in use today among home-schoolers and certain religious schools. The book's content ranges from basic alphabet, word, and sentence development found in previous books to connecting religious, moral, and ethical principles through excerpts from popular writing and speeches (McGuffey, 1879). In this sense, portions of the books featured authentic language, but the authentic texts were often too challenging for students to read or too unconnected with their personal experiences to be of much use in daily life. However, the series did introduce several ideas commonly found in textbooks today: teacher notes, the principle of recycling/reinforcing content in subsequent chapters, questions at the ends of chapters, and the principle of grading content so that each lesson and each level showed increased difficulty in terms of vocabulary and structures. A key aspect of The McGuffey Readers focused on a phonics method of sounding out each word.

The history of textbooks has vacillated between adapting and reacting against what has gone before, sometimes tempered by a better understanding of learners and learning processes. In terms of grading their content, The McGuffey Readers also illustrated the move away from the assumption that children were simply small adults and toward the realization 
that they needed learning materials tailored to their own interests. It was a successful formula, and more than 130 million copies of the readers have been sold.

\section{The Birth of the Student Centered Textbook}

In comparison to her impact on first language and second language acquisition, Zerna Sharp (1889-1981) is a surprisingly little-known figure. She began her career working first as a teacher and then as a school principal in the American mid-west. As she traveled from school to school, she became aware that young students were exhibiting reduced reading levels. It was her contention that part of the problem was motivation; it was a novel idea at a time when schools were largely seen as competitive institutions with those of ability rising to further academic challenges and training while those who did not demonstrate the necessary aptitude dropped out of the educational system to find low-level employment.

Sharp thought students needed motivating materials beginning with a change in the characters that were depicted on the pages of the book; she decided that these characters should be as close in appearance and behavior to the target readers as possible. Sharp also felt that rather than present each vocabulary item only once before moving on, the presentation and practice of such items should be repeated frequently for continuous reinforcement. She hit upon a formula of students learning one word at a time, repeated every third page. She also abandoned The McGuffey Readers' phonics approach, instead embracing whole word learning.

Sharp also thought that the words being taught should already be familiar to the students; it was the beginning of the trend to feature age appropriate language and age appropriate content. But Sharp's major inspiration came in a snippet of conversation overheard while walking near the beach. A child cried out, "Oh! Look! Oh, oh, look!" Sharp considered it a perfect fit with her ideas and incorporated the style of the utterance into a new series: Dick and Jane (Genovese, 2012; Kisemerick \& Heiferman, 1996; Norton Museum of Art, 1997).

Dick and Jane first appeared in 1927, released by the American publisher Scott Foresman. Sharp did not write any of the books in the series but rather worked as a consultant for the publisher. It is difficult to overestimate the impact of the series. By the 1950s, an estimated 80 percent of American first-graders who were learning to read were doing so with Dick and Jane books.

The book series quickly spread to other national markets as well. From the start, authenticity was a key concern of the series though, surprisingly, not always in terms of language. A typical sample of text ran, "Oh, father. See funny Dick. Dick can play. Oh, mother. Oh, Father. Jane can play. Sally can play.” It is ironic that although the series started with an authentic utterance, by the time it ceased publication in 1970, it had become a much-parodied exemplar of artificial language.

The ways in which the series did try to maintain authenticity was through the depictions of situations in which children found themselves, primarily domestic routines and play. The family unit consisted of a nameless mother and father, the central character of an older son, Dick, and his two younger sisters, Jane and Sally. There were also pets, a dog named Spot and a cat named Puff (note: names varied across editions). Mother was a housewife, raising the children, and father worked at some vague office job, which was never made clear. Sharp maintained control over the look and feel of the series, and each year she would consult department store catalogs to pick out appropriate clothing for the children and adults in the series. Toys (e.g., roller skates), appliances (e.g., electric stoves) and other possessions (e.g., automobiles) were similarly updated.

In the context of the times, these various toys, appliances and possessions can be seen as being inauthentic in terms of the general readership; within two years after the books were introduced, the world found itself in the midst of what became known as The Great Depression after the economic collapse of American stock markets in 1929. In this light, the depictions of everyday life of a relatively wealthy and certainly carefree family would seem inauthentic. However, there was perhaps another concern in effect: the books were aspirational (Kisemerick and Heiferman, 1996) in the sense that they portrayed a better material life for most readers - an unspoken promise of sorts that "good times" would return in time.

Regional varieties of the books offered authenticity in terms of depictions of local contexts. There were also editions for religious groups; both Catholic and Seventh Day Adventist editions were developed as early as the 1940s. In these versions, the characters were renamed and the contexts expanded to include religious instruction at home, visits to churches, and attendance at vacation Bible schools. Within the confines of the repetitive language structures, moral and religious instruction was included.

The Dick and Jane series became an industry of multiple publications across various formats. For example, Gardner (n.d.) writes,

Besides the paper books with staples and cloth tape spines, there were also Dick and Jane hard cover books, workbooks, guide books, posters, puzzles, calendars, napkins, valentines, mugs and teacher 
manuals. There were picture books without words for pre-readers, and there were pre-primers (We Look and See, We Work and Play, We Come and Go), the Junior Primer (Guess Who), and the Primer (Fun with Dick and Jane). Dick and Jane also taught basic hygiene and health in Good Times with Our Friends (para. 5).

However, in terms of authenticity in reflecting American life, there was one major inadequacy; between its introduction in 1927 and 1965, the series failed to include a single black character or characters of any other race. To place this in context, in 1930, the American census showed that 11.9 million people were black, accounting for 9.7 percent of the population. By the 1960s, these figures had risen to 18.9 million blacks making up 10.5 percent of the population. Yet they remained invisible in the very books black students used to learn to read.

A year after America's passing of the Civil Rights Act in 1964, and all its attendant publicity, Scott Foresman introduced a new series, this one featuring a black family with Dick's role taken over by Mike and Dick's sisters' roles taken over by the twins Pam and Penny (Martin, 2006). Almost everything about this new series was identical to the original Dick and Jane. The parents had the same roles with the father working in an office and the mother at home. The children from the two series interacted and played together in a move toward depicting racial harmony. However, it was not enough to save the series, which ceased publication five years later.

A major change that led to the death of the series consisted of a swing of the pendulum back in favor of phonics. There was also an issue of authenticity: what many saw as a negative portrayal of gender roles.

The sexual stereotypes in the Dick and Jane series were, in some ways, authentic. At the time of their writing, many American women were more likely to stay at home to care for children and assume most of the burden of domestic duties, in particular cleaning the house, doing laundry, and cooking meals. In the books, the father and Dick were seldom if ever portrayed as taking part in these duties. In one book, when father is found in the kitchen, he is seen making breakfast for himself (pancakes) rather than cooking a meal for the family. Conversely, the daughters of the family were often seen helping the mother with cleaning and the preparation of food.

The gender roles were sharply marked among the children, exacerbated by the difference in age between Dick and his younger sisters; Dick is always seen as the instigator of activities and the one most proficient at them. He is admired for climbing a tree by his parents and sisters; when not observing, the sisters often engage in comical attempts to do something not quite as difficult. Although the series made major attempts at authenticity that led it to be aspirational, it did not go far enough in extending those aspirations to recognizing the changing roles of girls and women.

The swing of the pendulum back to phonics instruction occurred through a number of attacks by those critical of the functional nature of Dick and Jane and its whole word approach. Critics also felt that the series narrowed learners' interest in reading beyond the textbook. For example, Shermer (2003) writes,

In 1955, Rudolf Flesch struck out against looksay readers in his bestseller, Why Johnny Can't Read. Flesch argued that the whole word method did not properly teach children how to read or to appreciate literature, because of its limited vocabulary and overly simplistic stories (para. 7).

Flesch was in favor of a return to the model of The McGuffey's Readers; one suspects it was the book series he used when learning to read. In 1967, alternatives to Dick and Jane began to appear in the form of The Open Highways series and others that included not just a return to phonics instruction but also common simplified children's stories, jokes and poems as part of their reading content. The Open Highways featured projects as well, such as creating a sock puppet or paper helicopter, as a way of teaching instructions.

\section{Literature, Authenticity and the Communicative Approach}

A greater move toward authenticity was fostered in the 1980s through the development of the Communicative Approach (Nunan, 1991). A key feature of the Communicative Approach is a focus on real language use in real situations with a particular emphasis on interaction. With its focus on authenticity, the Communicative Approach swung the pendulum against the directions set by The McGuffey's Readers and The Open Highways series.

The focus on real language did not completely do away with the teaching of literature or its use in instruction, but it dismissed phonics as an approach to learning to read in favor of ensuring students' ability to interact with others to communicate and negotiate a wide range of tasks. Where The McGuffey's Readers and The Open Highways series focused on recitation, new Communicative Approach texts focused more on using language as a tool of communication. Speaking and listening are foregrounded in the Communicative Approach, and fluency began to be thought of as more important than grammatical precision. Thornbury (2010) summarizes a communicative activity as featuring some or all of the following characteristics:

- purposefulness: speakers are motivated by a communicative goal (such as getting information, making a request, giving instructions) and not 
simply by the need to display the correct use of language for its own sake;

- reciprocity: to achieve this purpose, speakers need to interact, and there is as much need to listen as to speak;

- negotiation: following from the above, they may need to check and repair the communication in order to be understood by each other;

- synchronicity: the exchange - especially if it is spoken - usually takes place in real time;

- unpredictability: neither the process, nor the outcome, nor the language used in the exchange, is entirely predictable;

- heterogeneity: participants can use any communicative means at their disposal; in other words, they are not restricted to the use of a prespecified grammar item (para. 2).

Many would claim that the Communicative Approach has become the dominant approach to teaching and learning a second language but criticisms abound. For example, the above conditions for the Communicative Approach are considered more of a menu than a prescriptive practice. For this reason, teachers and materials developers tend to revert to a mixed methods approach, taking from the Communicative Approach those portions that they feel comfortable teaching and integrating older approaches, such as phonics, when it suits them.

In terms of language learning, this has resulted in hybrid textbooks that, like teachers, employ a variety of methods in reaction to market demand and perceptions of student needs. Consider the following dialog and consider whether it would qualify as an example of authentic English:

Star: How many robots do you have?

Emma: One.

Star: What color is it?

Emma: It's red.

Star: How many dinosaurs do you have?

Emma: Seven.

Star: What color are they?

Emma: They're green and yellow.

Star: How many dinosaurs does he have?

Emma: None (Beatty, 2012, p. 38).

Most native English speakers would say that although the individual sentences are authentic, the dialog is not. The individual utterances have several aspects that mark them as more authentic than texts from preceding ages, for example, the use of single-word answers where earlier books might have encouraged the use of full sentences. The use of contractions is also a mark of recognizing the realities of spoken English versus more formal written English.

But there are other details that clearly mark the dialog as inauthentic. For example, Star (a character/ mascot from space in the form of a young, purple- haired astronaut) asks what even children would consider obvious questions. In the illustrations for this dialog, the two characters are in the same room and the toys are clearly visible or, in the case of the last question, not visible. Therefore, questions about the number and the colors would seem redundant.

However, just as obviously, the dialog has a nonauthentic purpose: pedagogy. Most teachers would recognize that it addresses a number of vocabulary and grammar functions: capitalization, punctuation, contractions (it's, they're), question words (how, what), numbers (including none in lieu of zero), colors and the names of toys. These are expanded upon in the rest of the unit, particularly choices of colors and toys for substitution tasks. The numbers recycle and reinforce those taught in an earlier unit.

How do we reconcile pedagogy and the need for authenticity? Is the above text a reasonable compromise?

\section{Results}

\section{Authenticity of Language in English for Academic Purposes}

Before considering authenticity at the level of an English for Academic Purposes (EAP) text, review the following three excerpts (Beatty, 2013; Beatty, 2015). Which of the three can be considered an example of authentic language?

1. A descriptive written text:

When he was 20 years old, Daniel Northcott began ten years of traveling the world with his video camera. Eventually, he would undertake trips across 42 countries on four continents, visiting different cities, warzones and sacred sites. He ended up with more than one thousand hours of film. At each special place he visited, he would also collect a small souvenir, often in the form of a circular or ball-shaped object. On one of his last trips, he visited a sacred cave in Mexico. The floor was covered with the ancient bones of people who had been sacrificed there. Daniel took one bone, despite the warning of his guide who said that Daniel would be cursed.

2. A transcription of an interview:

Smith: Of course! My mistake. Since 2007. It's sort of a meeting of geniuses and inventors, isn't it?

Fox: (laughs) Well, I'm not sure how many people would call themselves geniuses, but actually, we have these beliefs about geniuses and inventors working alone but truthfully many innovations come out of the work of groups. Even the great scientist Isaac Newton said, "If I have seen farther, it is by standing on the shoulders of giants." His own - Smith: Did you say giants? What do you mean by giants? 


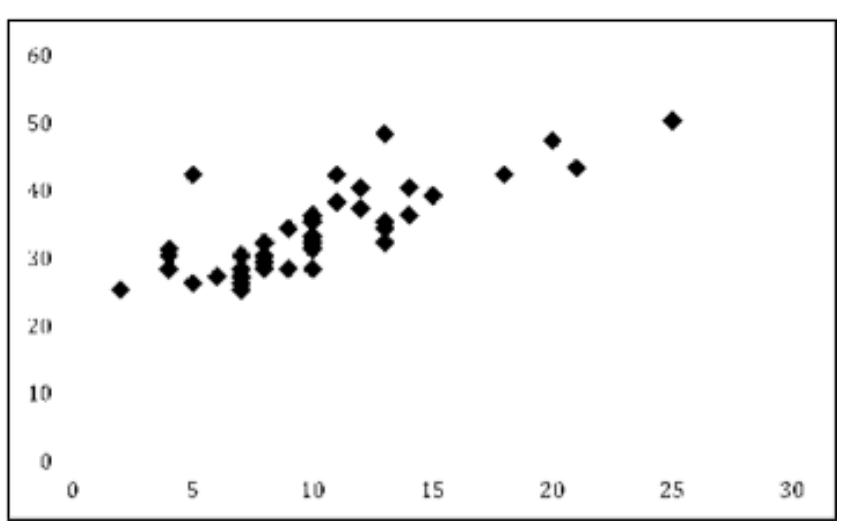

Figure 1. Age relative to experience.

Fox: Newton meant his ideas and inventions were based on the work of the great scientists who came before him.

3. A transcription of a speech:

Right back to the first breaking news event that is associated with Twitter's incursion into daily journalism, which was the Hudson River plane crash. And that involved a ferry operator - or passenger, rather, on a ferry - the operator was taking the ferry to the rescue scene on the Hudson River. And he took a snap on his mobile phone of the plane crashed into the river, which you could recognize if you saw it, and that became viral almost instantly as a result of him posting it on Twitter, via his mobile phone, and it was shared around the world.

If you faced more than a moment of indecision on selecting the third passage as the only authentic one, you are not alone. In an informal survey (through a show of hands) of 40 Canadian teachers attending a conference in Vancouver, Canada, and a more formal survey with 56 graduate students and faculty at Sabana University in Bogota, Colombia there was a common lack of agreement on which of the passages were authentic.

Beyond the informal Canadian survey, the Sabana University survey collected personal/ professional data to explore any correlation between the respondents and their answers. The Sabana students and faculty had between two and twenty-five years of teaching experience. Their focus was divided between primary/elementary school (39 percent), secondary school (42 percent), and university (19 percent) with a 70/30 split between females and males. Of the 56 respondents, only three were able to correctly identify the relative authenticity/inauthenticity of all three passages. Many inverted the choices, considering the third passage as being inauthentic and the other two as authentic.

Figure 1 indicates a common correlation between the age and experience of the teachers. The three teachers, all female, who selected all the correct

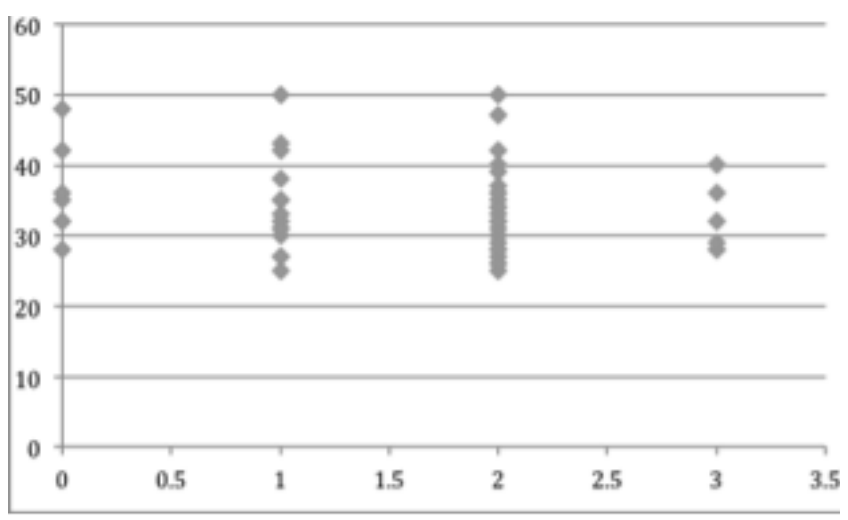

Figure 2. Age distribution of correct answers.

answers, were in the middle range of age and experience. With such a small sample of correct answers, there appears to be no statistical significance to correlating factors of gender, age or experience; the likelihood of chance being the determining factor is as strong as other factors.

Although many teachers identify authenticity in language learning materials as an important consideration, their inability to correctly identify them is worth investigation. Does it point to a need for training in terms of recognizing what constitutes authentic materials? To answer this question, it is necessary to examine the excerpts.

Passages 1 and 2 were both written by the author with the intention of mimicking authentic text and, not surprisingly, include aspects that might lead one to consider them authentic. For example, the first passage has the high degree of coherence and cohesiveness one would expect in a formal written document, in this case what one might commonly read in a magazine. As Excerpt 1 is drawn from authentic materials, it can be considered to be an example of constructed text.

Similarly, Excerpt 2 indicates aspects of the spontaneous language one would expect in an interview. Specifically, the passage includes a non-sentence (Since 2007.), contractions, an interruption, an indication of laughter, and a placeholding word (i.e., well) that serves to transition from the laughter to the speaker's comment. Along with place-holding words such as $u m$ and $u h$, most of the features in this and the third passage are seldom encountered in language textbooks. Nunan (1999) explains that,

There are few of the over-laps, hesitations, and false starts found in authentic texts and there is very little negotiation of meaning. These differences do not always adequately prepare learners for dealing with genuine communication either inside or outside the classroom, because some of the features of authentic 
communication that rarely appear in non-authentic texts (such as repetition, requests for clarification, and so on) actually facilitate comprehension. Also, the use of authentic sources leads to greater interest and variety in the material that learners deal with in the classroom (p. 212).

Nunan's comments highlight some of the features, as well as the problems, inherent in the third passage, an excerpt from a speech. Although it is authentic, it would seem to be an abysmal model for language learners. Consider Table 1.

However, learning opportunities can be drawn from both positive and negative models. In the case of this third passage, its shortcomings as a model can be used to illustrate common features of speech that students can both learn to recognize in oral discourse as well as use as strategies in their own conversations and oral presentations.

Table 1

Errors in a Speech Passage

\begin{tabular}{ll}
\hline Text of a speech passage & Error comments \\
\hline Right back to the first & This is an example \\
breaking news event & of an incomplete \\
that is associated with & sentence. \\
Twitter's incursion into & \\
daily journalism, which & \\
was the Hudson River & \\
plane crash. &
\end{tabular}

And that involved a ferry operator-or passenger, rather, on a ferry-the operator was taking the ferry to the rescue scene on the Hudson River.

And he took a snap on his mobile phone of the plane crashed into the river,

This is an example of the speaker making a mistake and correcting herself.

This is an example of an unclear antecedent; the he should refer to the passenger, not the last person mentioned, the operator

which you could recognize This is an example if you saw it, of the speaker interrupting herself.

and that became viral almost instantly as a result of him posting it on Twitter, via his mobile phone, and it was shared around the world.
Three of these oral strategies are repair, qualification, and elaboration techniques. The term repair (Fromkin, 1971) refers to correcting an utterance, usually mid-sentence. There are variations, such as an interlocutor interrupting to correct the speaker (e.g., "You mean, don't you?") but repair is most commonly done by speakers who realize that their own word or phrase has been misspoken. In Excerpt 3, the phrase, "or passenger, rather" is an example of repair and the use of rather signals that it is a revision to what has been said. In making a repair, Levelt (1983) suggests there are three steps: a pause in the flow of speech; an interrupting word or phrase (e.g., $I$ mean, that is, I should have said, What I meant was, sorry) called the editing phase; and then the repair in which the proper word or phrase is inserted into the conversation. Students who recognize repairs and are able to undertake them in their own speech come closer to native speaker proficiency.

Qualification refers to an elliptical interruption in the speaker's flow of discourse that sets conditions about what is being explained or discussed. As with repair, there is a pause and an interruption phase, often signaled with expressions such as except for, although not, unless and excluding. Qualifications are often found in tentative speech where the speaker does not want to over-commit to an idea.

Elaboration is the opposite of qualification; it adds information to make some portion of the speaker's message clearer. Elaborations are marked by words and phrases such as: for example, as seen in, for instance, and which can be explained as. Elaboration often occurs in a conversation when one's interlocutor exhibits non-verbal cues of incomprehension, such as a frown.

But it is not enough to introduce examples of repair, clarification, and elaboration; tasks need to be created that are able to operationalize them in ways that engage the student and make learning memorable.

\section{Discussion}

\section{Authenticity of Task}

Authenticity in tasks is a challenge in language education because the classroom context makes most tasks inherently false.

Typical of a pedagogical context are the following three pre-reading tasks (related to the third excerpt), all aimed at awareness-raising; none are requests for information or questions one would normally encounter in a real world context.

1. In the following excerpt from Listening 1, note how the speaker, Julie Posetti, uses questions in addition to 
repair, qualification and elaboration techniques to add content and effect to her presentation.

2. Rewrite the excerpt of Posetti's speech from task $B$, leaving out the questions and the repetitive aspects of repair, qualification and elaboration.

3. With your partner, compare your rewrites in task $C$ to the original speech. Discuss how the use of questions, repair, qualification and elaboration clarifies information and adds effect to Posetti's speech (Beatty, 2013, p. 68).

Similarly, after the students have read the complete passage, there are post-reading comprehension tasks:

1. Why is breaking news likely to come from social media rather than local reporters?

2. What is a viral story? Give an example?

3. The diagram suggests that the news cycle is shortened in some cases and lengthened in others. Why and how would this occur?

4. If you're really interested in a story, you can usually look up archived content online for more details. How does this differ from access to story backgrounds in traditional media? (Beatty, 2013, p. 65)

Although these are closer to questions one might have in a real world conversation, they still feature the diction one associates with classroom teacher discourse (i.e., teacher talk).

Within the chapter in which Excerpt 3 is featured, there are three pedagogical tasks that, once awareness has been raised, allow students to engage in an authentic activity. The first authentic task is to summarize a portion of the speech; although this is an academic skill, it is common in the real world, for example, in response to the question, "What was she talking about?" The second task is to have students take notes, a common authentic task in Academic English as well as in other contexts as mundane as scribbling a recipe during a television cooking program. The third task involves having the students create a podcast based on authentic reactions to an authentic news story:

Warm-up Assignment: Prepare a Short Podcast on a News Event

Podcasts often feature interviews or speeches. In this assignment you will prepare and deliver a short speech and, after, answer questions on it. All speeches try to share information in a logical way that answers basic who, what, when, where, why and how questions and also engages the listener to reflect on the content presented (Beatty, 2013, p. 77).

The authenticity of this task lies not just in its focus on a real world context but also on the opportunity to make choices, allowing students to individualize the task, essentially choosing their own topics within the general format. There is a specific reason for structuring tasks in this way, particularly in the academic English classroom. When everystudent is given anidentical task it encourages competition, the hoarding of resources and, in extreme cases, cheating and plagiarism for students who feel they cannot compete or cannot be bothered to compete. However, when students are given the option of individualizing their assignments, it creates opportunities for collaboration; students naturally share their work without concern for their peers gaining an unfair advantage. A related benefit is that students comparing their work tend to use the target language to engage in negotiation of meaning and peer-learning. It also means that personal misunderstandings of the assignment are likely to be settled through clarifications by other students.

\section{Authenticity of Situation}

Authenticity of situation is among the most challenging aspects of authenticity for classroom teachers to provide to their students. Using the example of a visit to a natural ecosystem during which science students would conduct an experiment to explore a hypothesis and then report on their findings, students would learn by doing,

... and they acquire the foundational skills, knowledge, and understanding that working scientists actually need and use in their profession. In this case, students would also learn related skills such as critical thinking, problem solving, formal scientific observation, note taking, research methods, writing, presentation techniques, and public speaking (Authentic Learning, para. 3).

This can be contrasted to a classroom experience where the approach is more theoretical and less likely to demonstrate the student's abilities to transfer learning to a real world context, such as in a job.

The same is true of in-class experiences in academic English studies. Although there are many classroom activities that are authentic in terms of preparing students for the demands of being a student, they are not necessarily authentic in terms of life after college or university. The usual solution is to offer fieldtrips to visit places where authentic English can be used or to assign homework assignments that accomplish the same thing. However such assignments are sometimes only practical in locations where English is the target language.

\section{Conclusion}

In striving for authenticity in language teaching and learning, teachers tend to choose materials on a continuum of inauthentic, constructed and authentic. Inauthentic materials are those created by the teacher for a pedagogical purpose with little connection to the real world. For example, multiple- 
choice tests are common in classrooms but relatively rare in the real world. Constructed materials are those adapted from real world examples, such as a simplified restaurant menu that replaces confusingly trademarked names (e.g., a hamburger instead of a Big Whopper) that unnecessarily add complexity. Authentic language, tasks, and situations come as close to the real world as possible.

Regardless of the degree of authenticity in language, tasks, and situations, there is an inherent inauthenticity in the selection process. For example, even if a teacher brings in a newspaper to class, choices will be made about what newspaper at what level. What should teachers do to engage students in more authentic materials, tasks and situations? The following are four suggestions:

1. Construct materials from authentic sources to familiarize students with language: vocabulary, structure and usage. This should be an intermediate step in moving students to engage with real world language, tasks and situations.

2. Develop student strategies to deal with the unexpected in authentic language, tasks and situations. One of the reasons teachers avoid authentic materials, tasks and situations is that they present language items which are either superfluous to students' needs or which are too complex for their level of comprehension. Solutions include teaching students strategies for understanding new vocabulary from context and clarification, particularly in spoken contexts (e.g., Could you explain what you mean by ?).

3. Create pedagogical scenarios for role-plays in which students play parts connected with their own realities. Traditional role-plays often focus on situations that are inauthentic for a student, for example, having primary school students pretending to be dentists and receptionists when their only likely role is to be patients. Instead, consider linking students to their own realities by exploring with them the language events they encounter throughout a typical day. Even if they do not use English in such situations outside the classroom, they are more likely to mentally rehearse what they have learned.

4. Create authentic materials students are likely to come across, and realistic L1 course content in terms of language, tasks and situations. But avoid reinventing the wheel, doing work that has already been done for you either by fellow teachers or in published materials.

Finally, while authenticity should be a goal, it should not overwhelm other considerations. Shomoossi \& Ketabi (2007) write,

\footnotetext{
"Both educators and materials designers need to stop thinking about authenticity as a dictated imperative having an 'either/or' quality but rather think of it as
}

being multifaceted and applicable to different phases of language classroom processes.” (p. 154)

Authenticity is important, but it should not overwhelm a teacher's attempts to offer creative student-centered pedagogy.

\section{References}

Authentic Learning. (2014, August 26). In S. Abbott (Ed.), The glossary of education reform. Retrieved from http://edglossary.org/hidden-curriculum.

Bardeen, C. W. (Ed.) (1887). The Orbis Pictus of John Amos Comenius (C. Hoole trans.). Syracuse, NY: C. W. Bardeen.

Beatty, K. (2012). Starship English student book 1. Orlando, FL: Houghton Mifflin Harcourt Publishing.

Beatty, K. (2013). Learning English for academic purposes. Advanced: Listening and speaking. Montreal, Canada: Pearson Canada.

Beatty, K. (2015). Learning English for academic purposes. Intermediate: Reading and writing. Montreal, Canada: Pearson Canada.

Dunkel, P. A. (1995). Authentic second / foreign language listening texts: Issues of definition, operationalization and application. In P. Byrd (Ed.), Material Writer's Guide (pp. 95-106). Boston, MA: Heinle \& Heinle.

Foster, J. (2012, September 2) Accidental mysteries, the design observer group. Retrieved from: observatory. designobserver.com/feature/accidentalmysteries-090212/35848/

Fromkin, V. A. (1971). The non-anomalous nature of anomalous utterances. Language, 47(1), 27-52.

Gardner, B. (n.d.). History of Dick and Jane readers. Editorial Today. Retrieved from: http://www. streetdirectory.com/etoday/history-of-dick-andjane-readers-uuewef.html.

Genovese, P. (2012, May 18) Look, look. Dick and Jane are back. Media History Project, University of Minnesota, Minneapolis, MN. Retrieved from www. mediahistory.umn.edu/archive/dickandjane.html.

Kisemerick, C., \& Heiferman, M. (1996). Growing up with Dick and Jane: Learning and living the American dream. New York, NY: William Morrow \& Company.

Levelt, W. J. M. (1983). Monitoring and self-repair in speech. Cognition, 14, 41-104.

Martin, M. (2006). African American Dick and Jane. University of Florida's Center for Children's Literature and Culture, Gainesville, FL. Retrieved from www.recess.ufl.edu/transcripts/2006/0223. shtml.

McGuffey, W. (1879). McGuffey's first eclectic reader. Van Antwerp, NY: Bragg and Company. 
Norton Museum of Art. (1997). Dick and Jane: Illustrations of an American education. Retrieved from: www.tfaoi.com/newsmu/nmus18d.htm.

Nunan, D. (1988). The learner centered curriculum. Cambridge, UK: Cambridge University Press.

Nunan, D. (1991, January 4). Communicative tasks and the language curriculum. TESOL Quarterly 25(2), 279-295.

Nunan, D. (1999). Second language teaching \& learning. Boston, MA: Heinle \& Heinle.

Rogers, C., \& Medley, F. Jr. (1988). Language with a purpose: Using authentic materials in the foreign language classroom. Foreign Language Annals, 21, 467-478.

Shermer, E. T. (2003). Reading with and without Dick and
Jane: The politics of literacy in 20th century America. Rare Book School. Retrieved from: http://www. rarebookschool.org/2005/exhibitions/dickandjane. shtml.

Shomoossi, N., \& Ketabi, S. (2007). A critical look at the concept of authenticity. Electronic Journal of Foreign Language Teaching, 4(1), 149-155. Retrieved from e-flt.nus.edu.sg/v4n12007/shomoossi.pdf.

Tatsuki, D. (2006, May 13-14). Authentic communication. In Proceedings of the 5th annual JALT pan-SIG conference. Retrieved from https:// jalt.org/pansig/2006/HTML/Tatsuki.htm.

Widdowson, H. (2012). Context, community, and authentic language. TESOL Quarterly, 32(34), 705716. 


\section{Appendix A}

\section{Running With Scissors: Authenticity in the Classroom}

Note: Completing this form signals your willingness to participate in this study. No personal information will be reported in the study or used for any other purpose. . $\square$ male $\square$ female. Age:

Name:

Sabana University Residential Group (check one) $\square 1 \square 2 \quad \square 3$

Years of teaching experience:

Grades or levels you have taught:

Please read the following excerpts and decide whether each is authentic or inauthentic.

Excerpt 1(check one):

$\square$ authentic $\square$ inauthentic

When he was 20 years old, Daniel Northcott began ten years of traveling the world with his video camera. Eventually, he would undertake trips across 42 countries on four continents, visiting different cities, warzones and sacred sites. He ended up with more than 1,000 hours of film. At each special place he visited, he would also collect a small souvenir, often in the form of a circular or ball-shaped object. On one of his last trips, he visited a sacred cave in Mexico. The floor was covered with the ancient bones of people who had been sacrificed there. Daniel took one bone, despite the warning of his guide who said that he would be cursed.

Excerpt 2 (check one):

$\square$ authentic $\square$ inauthentic

Smith: Of course! My mistake. Since 2007. It's sort of a meeting of geniuses and inventors, isn't it?

Fox: (laughs) Well, I'm not sure how many people would call themselves geniuses, but actually, we have these beliefs about geniuses and inventors working alone but truthfully many innovations come out of the work of groups. Even the great scientist Isaac Newton said, "If I have seen farther, it is by standing on the shoulders of giants." His own-

Smith: Did you say giants? What did he mean by giants?

Fox: He meant his ideas and inventions were based on the work of the great scientists who came before him.

Excerpt 3 (check one):

$\square$ authentic $\square$ inauthentic

Right back to the first breaking news event that is associated with Twitter's incursion into daily journalism, which was the Hudson River plane crash. And that involved a ferry operator-or passenger, rather, on a ferry-the operator was taking the ferry to the rescue scene on the Hudson River. And he took a snap on his mobile phone of the plane crashed into the river, which you could recognize if you saw it, and that became viral almost instantly as a result of him posting it on Twitter, via his mobile phone, and it was shared around the world. 